\section{Investigation of nausea and vomiting in cancer patients undergoing chemotherapy}

Maria Lavdaniti, Nikolaos Tsitsis

Alexander Technological Educational Institute of Thesaloniki, Greece

\section{Abstract}

Nausea and vomiting are the most important problems in patients undergoing chemotherapy, despite the recent improvements in the administration of antiemetic drugs. Through a review of the literature, we found that there are several nursing researches focusing on the effectiveness of interventions for the treatment of nausea and vomiting in cancer patients. The purpose of this study was to investigate the symptom of nausea and vomiting in patients undergoing chemotherapy. The study also investigated the impact of nausea and vomiting on patients' ability to respond to daily activities. The study is descriptive; the sample included patients with different types of cancer and receiving chemotherapy. The inclusion criteria were: the histological diagnosis of cancer, the administration of chemotherapy and the knowledge of the Greek language. The questionnaires used were: the MASCC (vomiting questionnaire), the Memorial Symptom Assessment Scale and the scale of functional assessment of cancer therapy. Data collection took place in oncological hospitals of Thessaloniki and Athens in Greece. For statistical analysis we used the statistical package SPSS 15.0.

\section{Introduction}

Cancer includes a group of diseases that is characterized by rapid growth of abnormal cells. If the spread of these cells is uncontrolled can lead to death. The causative factors of cancer may be exogenous (e.g. smoke, infectious organisms, radiation, chemical agents) and endogenous (e.g. hormonal factors, heredity, mutations). 1

Cancer is one of the main factors of death worldwide since, according to the data from the World Health Organization, in 2008 it caused 7.6 million deaths (the $13 \%$ of the deaths). ${ }^{2}$ It is estimated that during the 2012, 1.638.910 new cases of cancer will be diagnosed in USA and 577.190 deaths will occur during the same year (American cancer society 2012). In Europe 3.2 million new cases appeared and 1.7 million of people die every year. ${ }^{3}$

The cancer treatment includes surgery, chemotherapy, radiotherapy, hormone therapy, treatment with biologic modifiers, targeted therapy. 1,4 The chemotherapy concerns the use of drugs that inhibit the cell division by inhibiting the synthesis of the genetic material or by causing damages to DNA. The use of chemotherapy in cancer aims to cure the disease (because destroys all the cancer cells), to control the disease (stop of development and of spread of the disease), and finally to the relief of the symptoms caused by the disease at the final stage (e.g. pain, breathlessness). The chemotherapy is a systematic treatment, cause a variety of side-effects that are caused by the damage also of normal cells of the body which multiply quickly (e.g. cells of the scalp, of the bone marrow, of the gastrointestinal).

Nausea and vomiting are the most common side-effects experienced by cancer patients undergoing chemotherapy. The nausea and vomiting caused by chemotherapy are divided into three categories depending on the time they appear: acute phase, delayed phase and the reflective phase. The acute phase is appeared into 24 hours after the administration of the chemotherapy, the delayed-onset phase is appeared by the first 24 hours to 3-5 days after, and the anticipatory phase is appeared in time that is not normally expected. There are various factors which contribute to the appearance of the symptom and are divided into two categories: the factors associated with treatment (e.g. type and dosage of chemotherapeutic drugs, route of administration) and the factors associated with the patient (sex, age, previous history of symptoms display, use of alcohol, concern, simultaneous administration of other drugs etc). ${ }^{5-7}$ There are four emetogenic potential of intravenous antineoplastic agents: high, moderate, low, minimal. 4,8

\section{Background}

The nausea and vomiting are one of the most important problems of patients undergoing chemotherapy,5,7,9,10 despite the improvements in antiemetic drugs administered to treat them. 11,12 The existence of symptoms affecting the maintenance of health professionals instructions for treatment, the decision to stop treatment and their willingness or capacity for food intake.4,7,13 It is estimated that approximately $70-80 \%$ of the patients receiving chemotherapy are at risk for nausea and vomiting, 4,13 while the same percentage of patients will experience the symptom if they have not received adequate antiemetic therapy. ${ }^{7}$ From the literature review found that a large part of
Correspondence: Maria Lavdaniti, Alexander Technological Educational Institute of Thesaloniki, GR 57400 Thessaloniki, Macedonia, Greece.

Tel.: +30.317.91100 - Fax: +30.231.079.9152.

E-mail: maria_lavdaniti@yahoo.gr

Key words: nausea, vomiting, chemotherapy, nursing.

Contributions: the authors contributed equally.

Conflict of interests: the authors declare no potential conflict of interests.

Received for publication: 4 April 2014 Revision received: 16 November 2014.

Accepted for publication: 17 November 2014.

This work is licensed under a Creative Commons Attribution NonCommercial 3.0 License (CC BYNC 3.0).

(C) Copyright M. Lavdaniti and N. Tsitsis, 2014 Licensee PAGEPress, Italy

Health Psychology Research 2014; 2:1550

doi:10.4081/hpr.2014.1550

nursing researches focus on investigating the effectiveness of interventions for the treatment of nausea and vomiting in cancer patients. ${ }^{14-16}$

In 2004, Glaus et al. investigated the occurrence frequency of nausea and vomiting in 243 cancer patients and the effect of symptoms on the realization of daily activities. The results obtained were percentage $42-52 \%$ of patients experienced the symptom and percentage of $38 \%$ experienced late form of the symptom. ${ }^{17}$ Most recently Mollassiotis et al. investigated the symptom of acute and delayed nausea and vomiting in 102 patients undergoing chemotherapy and the change of this symptom. The results reported that during the first cycle of chemotherapy patients experienced the acute and delayed form of the symptom, the frequency of which increases during chemotherapy. ${ }^{10}$ In 2011 Mollassiotis et al. studied the existence of symptoms of nausea and vomiting and the effect on the psychological and nutritional status of 104 cancer patient undergoing chemotherapy. They found that patients experienced the symptom that influenced the psychological status, the nutrition and ultimately the quality of life of patients. ${ }^{18}$

The originality of the research lies in the fact that in Greece have not been detected, until now, studies involve the investigation of nursing symptom in patients with cancer. Researches already contacted concern the effectiveness of different antiemetic agents to treat nausea and vomiting. 19-21 


\section{Purpose of the study}

The purpose of this study is to investigate the symptom of nausea and vomiting in patients undergoing chemotherapy. More specific, it will determine the frequency of the symptom in cancer patients, and the coexistence of other symptoms experienced by patients during the chemotherapy. The study will also investigate the impact of nausea and vomiting on patients' ability to respond to daily activities.

\section{Methodology}

\section{Sample}

This is a descriptive study, the sample of which consisted of patients with different types of cancer receiving chemotherapy. The criteria that must be met by the patients in order to entry in the study are the following: the histological diagnosis of the cancer, the administration of chemotherapy and the knowledge of the Greek language. Patients who experience nausea and vomiting due to some other causes and patients undergoing concurrent chemotherapy and radiation are excluded from the study.

\section{Measurement tools}

For the purposes of the study there will be used the most appropriate tools for measuring variables. The choice of these tools will be made by the international literature. The tools will be used are: the MASCC (vomiting questionnaire), the Memorial Symptom Assessment Scale (MSAS) and the scale of functional assessment of cancer therapy (FACT).

\section{Data collection}

The data collection will take place in oncological hospitals of Thessaloniki and Athens. Initially, a pilot study will take place in order to investigate the comprehension of questionnaires from patients and there is the possibility of a modification of data collection tools.

\section{Statistical analysis}

For the statistical analysis of the survey data will be used the statistical package SPSS 15.0 for windows. After the coding of responses, for data analysis will be used statistical methods of descriptive and conductive statistics.

\section{References}

1. American Cancer Society. Cancer facts and figures. 2012. Available form: http://www. cancer.org/acs/groups/content/@epidemiologysurveilance/documents/document/ac spc-031941.pdf

2. WHO. GLOBOCAN 2012: section of cancer information. Available from: http://globocan.iarc.fr/Default.aspx

3. Ferlay J, Autier P, Boniol M, et al. Estimates of the cancer incidence and mortality in Europe in 2006. Ann Oncol 2007;18:581-92.

4. NCCN. NCNN clinical practice guidelines in oncology. 2012. Available from: http://www.nccn.org/professionals/physician_gls/f_guidelines.asp

5. Lohr J. Chemotherapy-induced nausea and vomiting. Cancer J 2008;14:85-93.

6. Hesketh PJ. Chemotherapy-induced nausea and vomiting. N Engl J Med 2008;358: 2482-94

7. Feyer P, Jordan K. Update and new trends in antiemetic therapy: the continuing need for novel therapies. Ann Oncol 2011;22:30-8.

8. Roila F, Hersted J, Aapro M, et al. Guideline update for MASCC and ESMO in the prevention of chemotherapy- and radiotherapy-induced nausea and vomiting: results of the Perugia consensus conference. Ann Oncol 2010;21:232-43.

9. Martin, CG, Rubenstein ED, Elting LS, et al. Measuring chemotherapy-induced nausea and emesis. Psychometric properties of a quality of life questionnaire. Cancer 2003;98:645-55.

10. Molassiotis A, Saunders MP, Valle J, et al. A prospective observational study of chemotherapy-related nausea and vomiting in routine practice in a UK cancer centre. Support Care Cancer 2008;16:201-8.

11. Hickok JT, Roscoe JA, Morrow GR, et al. Nausea and emesis remain significant problems of chemotherapy despite prophylaxis with 5-hydroxytryptamine-3 antiemesis: a University of Rochester James P. Wilmot Cancer center community clinical oncology program study of 360 cancer patients treated in the community. Cancer 2003;97:2880-6.

12. Tipton JM, Mcdaniel RW, Barbour L, et al.
Putting evidence into practice: evidencebased interventions to prevent, manage and treat chemotherapy-induced nausea and vomiting. Clin J Oncol Nurs 2007;11: 69-78.

13. Vidal C, Dielensenger P, Farell C, et al. Evidence-based management of chemotherapy-induced nausea and vomiting: a position statement from a European cancer nursing forum. Ecancermedicalscience 2001;5:211.

14. Genc A, Can G, Aydiner A. The efficiency of the acupressure in prevention of the chemotherapy-induced nausea and vomiting. Support Care Cancer 2013;21:253-61.

15. Yeh CH, Chien LC, Chiang YC, et al. Reduction in nausea and vomiting in children undergoing cancer chemotherapy by either appropriate of shum acupuncture points with standard care. J Alter Com Med 2012;18:334-40.

16. Suh EE. The effects of $P 6$ acupressure and nurse-provided counseling on chemotherapy-induced nausea and vomiting in patients with breast cancer. Oncol Nurs Forum 2012;39:E1-9.

17. Glaus A, Knipping C, Morant R, et al. Chemotherapy-induced nausea and vomiting in routine practice: a European perspective. Support Care Cancer 2004;12: 708-15.

18. Molassiotis A, Brearley SG, Stamataki Z. Use of antiemetics in the management of chemotherapy-related nausea and vomiting in current UK practice. Support Care Cancer 2011;19:949-56.

19. Pectasides D, Dafni U, Aravantinos G, et al. A randomized trial to compare the efficacy and safety of antiemetic treatment with ondansetron and ondansetron zydis in patients with breast cancer treated with high-dose epirubicin. Anticancer Res 2007;27:4411-7.

20. Stathopoulos GP, Antoniou D, Dimitroulis $\mathrm{J}$, et al. Liposomal cisplatin combined with paclitaxel versus cisplatin and paclitaxel in non-small-cell lung cancer: a randomized phase III multicenter trial. Ann Oncol 2010; 21:2227-32.

21. Katsenos, S, Psara, A, Panagou, C. Pemetrexed-induced cellulitis: a rare toxicity in non-small cell lung cancer treatment. Oncol Pharm Pract 2013;19:93-4. 